\title{
IsTVÁn MAgAS
}

\section{Post-Crisis PATterns Of EXTERNAL ADJUSTMENT}

\section{IN SOME SMALL OPEN ECONOMIES}

\author{
Financial Adjustments to External Shocks: Empirical eVidence \\ FROM SOME EU-MEMBERS AND TRANSITION COUNTRIES (1993-2014)
}

\begin{abstract}
In this paper there were two types of international financial adjustment patterns identified: type-A, where highly independent monetary policy and low domestic currency stability was the preferred path; and type- $B$, where monetary policy independence was given up and currency stability was acquired. We argue that whichever type of external financial adjustment the preferred path may be, the ability to resist major external shocks simultaneously depend on a handful of other macro prudential factors (e.g. fiscal and debt service performance), too. A country may not be euro-zone member and still do well in the shock resistance department, like the Czech Republic. For Hungary, euro-zone membership would sure bring better shock resistance capabilities, yet, it would in no way offer solution to the existing deficits in its levels of international competitiveness and productivity.
\end{abstract}

\section{INTRODUCTION}

Beginning in the early 1990s, and following the huge run-ups in international financial flows up until the 2008-2009 crises, to what extent did the foreign-trade-sensitive small open economies follow standard patterns in their external adjustment? That is our main question. Our concise answer is: the adjustment-patterns to be observed were not just very different in their profiles, but they also showed many variations with respect to the keys of their success. In this paper, we shall examine, however, whether how some central European small open economies, and Hungary in particular, could further increase their ability to resist external shocks.

We shall demonstrate that, yes, when we compare the pre-crisis period of 1994-2007, with the post-crisis years, 2008-2014, overall, the small open economies, mostly trade-sensitive countries in our sample, could and did manage to improve their external shock-resistance capabilities.

During the most intensive phase of financial globalization, namely throughout the years of 1994-2007, it was widely assumed that the proposition of the so called impossible trinity principle was an iron law, the violation of which threatened with most heavy penalties, including a financial collapse, as a possible outcome.

The evidence that this paper provides, for most of the countries analyzed, is to support, that indeed, the power of the trinity proposition did prove to be very hard to go against. The simultaneous presence of three key factors, that of the foreign exchange price stability of the home currency; the preservation of the monetary independence of the home country's central bank; and the maintenance of largely (or fully) open capital(financial) accounts; was hardly possible, no matter which country we put in the focus of statistical analysis. To test and thus to prove the power of the impossible trinity proposition we shall look at the so called trilemma indices for a group of 12 selected small open economies with a sharper focus on small European Union member countries. 
The observed "test period" chosen and applied for the comparison, will be almost two decades long, namely we study the years of 1993-2014.

What we wish to examine more specifically is the relevance and strength of the trinity proposition, especially when it comes to address the various patterns of external adjustments. We are posing one concrete main question: based on the trilemma indices, were there typical successful adjustment patterns to be identified from the appearing adjustment paths? Or, there were several types of patterns which could, in their own way, all be labelled as successful based on some unique criteria?

The approach applied for the analyses will be model-based and empirical when assessing the trilemma indices for the selected small open economies.

Although the impossible trinity proposition itself is not up to strict mathematical rigor, yet when it comes to produce good measurements, following the Aizenman (2010) and Aizenman et al (2013) methodology, one finds adequate parameters to proxy even if they do not properly match the designed simultaneous delivery of foreign exchange stability, monetary independence and open capital accounts. In essence, we want to confirm the claim that there are massive tradeoffs between simultaneous efforts to have any two policy options, i.e. to select any pair of the trilemma legs, without compromising the left-out third leg of the three adjustment channels. For instance, to have ongoing fx-stability and monetary independence at the same time, one should have strict capital account controls. In the absence of the latter - i.e. with floating rates and open capital accounts - one should allow for large fx-instability. The unavoidable result: countries with such policy options shall give up a good amount of their monetary independence to be able to offset the fx-instability consequences.

As one of the most important findings of the paper, we wish to show that, in fact across the entire country sample, the capital-account openness became a generally shared attribute. This universally very liberal stance of treating current account transaction to help international capital flows more across national borders was accompanied with quite varied levels of fx-stability and those of monetary independence, respectively.

In the detailed analysis, we shall demonstrate that one could identify two major versions of external adjustment-policy paths. We have classified these two adjustment versions as type-A and type-B, respectively. Type-A is the "traditional" small open economy external adjustment profile in which monetary independence is preserved to a large degree, and where - given the open capital account - it is the fx-stability that plays the role of the primary shock absorber. Amongst the EU-members, Hungary and the Czech Republic represented this type-A policy choice, for example. The other typical option was to be identified with a guaranteed maintenance of fx-stability, and thus with the giving up of monetary policy independence. This was the pattern always when we talked about a member of the euro-zone. Such typical euro-zone membership patterns were followed by Austria, Slovenia, Slovakia, Portugal and Greece; and also to this group belongs, true somewhat as an outlier, Denmark, who, while keeping its own currency, the krone, was tightly matching/following the ECB monetary policy.

After the introduction, in section 2, we shall briefly review the relevant early theoretical foundations, namely the Mundell-Fleming model. Next, we shall discuss its modern extensions. In section 3, we exhibit and comment on the behavior of the trilemma indices for both types of adjustment patterns covering the 1993-2014 period. The paper ends with a summary and conclusion section. 


\section{External Shocks for a Small Open Economy}

\subsection{GUIDELINES FROM THEORY}

Established analytical frameworks such as, Mundell (1968), Kenen (1989), Obstfeld (2015) as well as their empirically counterparts e.g. Aizenman (2010), have long emphasized the multiple dilemmas deriving from the search for a single, optimal-policy-oriented model. The mentioned works have all especially pointed to the vulnerabilities caused by sudden and massive foreign capital inflows in the accumulation of excessive foreign debt and in moderating fx-instability. In this regard, there are a handful of general policy guidelines that older and current mainstream theories have put on the table for quite some time.

A. Policy oriented models can show how monetary and fiscal policy must be used jointly with exchange rate changes to maintain internal and external balance. To obtain optimal policy combination by successive approximation each instrument should be assigned to the target on which it has the greatest relative effect. We would therefore expect the foreign exchange rate to be used for adjustment of the external balance, and fiscal (tax and expenditure) policies to be used for internal balance.

B. We would add that in wide open economies, however, with large marginal propensity to import, the conventional assignment should be reversed! In addition, in these very open economies with flexible exchange rates, large and sudden changes in fiscal and monetary policy can cause explosive oscillations especially if policy changes are taking place without allowing for the fx-rate effects to follow suit. In the crisis months of 2008-2009, for many small open economies this outcome has rapidly proven to be doing a lot of damage.

C. With open and/or largely liberalized capital accounts central banks cannot choose independently targets for both the money supply and the fx-rates. If they do, they immediately create conflicting adjustment paths for the economy and policy instruments work against each other and produce messy outcomes. This proposition is known as the impossible trinity as established, by strict metrics, in Aizenman et al. (2013). In other words, to ease the trilemma, only relatively good pairs can be chosen from the policy toolbox, containing fx-stability, monetary independence and globally integrated capital accounts. Any two selected out of the mentioned three policy tools, automatically inhibits the application and proper use of the left-out third leg.

D. As a general rule, governments must almost always allow market forces to determine either the money supply or the $\mathrm{fx}$-rate to find equilibrium levels. To swim against the stream for long could be very costly and can lead to financial exhaustion. In Hungary, this pattern was showing exceptionally strong vulnerability in her external finance. This proposition finally was understood in 2008, in the climax of the financial crisis, and with it the IMF loan accepted. ${ }^{1}$ Thus it showed how the hands of central banks action are tied when they need to choose between foreign exchange(fx)-stability and full monetary independence. The classification of small open economy trinity profiles are exhibited in Table 2 (as you can see later).

E. In an open economy with floating exchange rates, the induced reduction in the demand for net exports (shrinking foreign markets) further reduces the power of fiscal expansion to stimulate aggregate demand in the short run.

F. In the context of current world economic trends for this year and for 2020, within reasonable bounds, the depreciation of emerging-market currencies is a normal and welcome adjustment to the fact that emerging economies enjoy a relatively better economic outlook than most OECD countries.

\footnotetext{
${ }^{1}$ See Benczes (2016).
} 
G. Appreciation means that some of the tightening in monetary conditions necessary in emerging-market economies will come from the exchange rate so that correspondingly less will be needed from domestic monetary policy. Or so would the theoretical argument go.

$\mathrm{H}$. The downside for emerging-markets and especially for small open economies is that, if the exchange rate moves by a large amount, it may lead to a rather uneven distribution of the adjustment burden with the exposed sectors, doing most of the adjustment and domestic sectors (and asset markets) being allowed to expand strongly. If the exchange rate movement is seen as a short-lived overshooting, this could be an argument for temporary intervention to smooth the adjustment. But there is always a risk that this line of thinking may be exploited to justify intervention in cases where it does not really apply. Even where intervention may have some basis, its implementation is fraught with difficulties.

I. There is broad convergence in empirical studies [as explained by Bohl et al. (2016)] on the finding that foreign-exchange intervention is not effective beyond the very short term, except if it is not sterilized. That is to say that intervention works only if domestic monetary policy moves in the same desired direction of adjustment. In particular, a country that intervenes to stem currency appreciation would have to make its domestic monetary policy more accommodative, with the risk of adding to consumer and asset price pressures. An alternative option is to try to curb capital inflows through taxation, deposit requirements and other tools. Such measures may have an effect in the short term but eventually foreign investors usually find a way around them. Controls of this nature are blind: while they may stop some speculative inflows, they are also bound to hurt productive investment. They are more effective and have fewer unintended side-effects when they are targeted at avoiding too large inflows of "hot" money that can suddenly become an outflow and lead to financial sector problems. There is some empirical evidence - as was confirmed by Rojas-Suarez (2015) - that capital controls can effectively shift the composition of inflows from short- to long-term investments. Even so, the first-best policy setting is not to target foreign capital inflows but to put in place regulatory and supervisory arrangements that make sure that the financial sector is resilient to funding shocks independently of their source.

\subsection{A Special Focus on Hungary}

Against these broad, yet sound theoretical guidelines we should mention that Hungary did, and does meet the very open, small economy with floating-fx-rate "trilemma-sensitive" criteria, and she has long, for almost two decades, been struggling with the right adjustment efforts to fund the twin-external and internal-deficits. Finding the optimal policy mix has never been easy, but in the world economic crisis environment that sent high shock waves, it was an extremely difficult assignment. For a while, in the early 2000s, the picture for policy makers seemed to improve somewhat as capital inflows into Hungary in the mid-2000s have been boosted primarily by attractive real rates, and by the good prospects linked to EU- related structural reforms and to lower sovereign risk premia thanks to the initially good signs of macroeconomic stabilization. Hungary attracted enough short- and medium-term capital by high real interest rates paid on government bonds (e.g., Benczes 2008). Furthermore, capital inflows tended to be associated with declining interest rates in the industrialized countries (compared to domestic interest rates) and with increased global liquidity. The result was an appreciation of the HUF in real terms. Another complicating factor has been the rapid growth of bank credit to the private sector, funded by bank borrowing from abroad. These changes have not only been important in stimulating the capital inflows, but have also ill-shaped the policy responses to the severe complications caused especially by the seemingly cheap foreign funds. The latter delivered heavy blows to Hungarian macroeconomic and financial stability. 
One of such lasting blows was the solution for long known Impossible Trinity dilemma: while opening the capital account and pursuing multiple policy objectives (price stability, external funds and competitiveness) policy tensions were likely to surface between domestic and foreign economic goals that were to be met simultaneously. They did. In theory, greater exchange rate flexibility can help to resolve the tension between various policy targets by letting the appreciation absorb the impact of the inflows. But in reality exchange rates could do little to make proper adjustments as emphasized by Bohl et al. (2016). Indeed, lasting volatility (as can be seen on Graph 1) of fx-rates could not help stabilization policies in a trivial fashion. This was the case for most CEE-countries in general and for Hungary in particular.

While common global shocks have increasingly affected the volatility of interest rate spreads and other financial indicators in Hungary, important factors behind the turbulence were the unwanted domestic banking and fiscal developments. When the crisis intensified in late 2008, liquidity and capitalization strains in particular in the banking sector shook financial markets. The results in the financial account of the balance of payments for Hungary - a deficit of 7.8 billion Euros in 2008, as compared to a surplus of 1.6 billion Euros in 2010 - show how soon and how drastically conditions tightened in the crisis hit international financial environment. In October of 2008 massive capital outflows, threatening by capital flight led to interventions by the Hungarian Central Bank (The National Bank of Hungary, NBH), and to an immediate 350 basis points increase in the base rate. New and large sovereign borrowing became necessary, along with the support from the international financial institutions. (IMF, EBRD). These rescue steps did, to a large extent, add to spur interest rate volatility to new highs, as negative shocks took off from the further weakened government credibility. In addition, special concerns about the long known cyclical effects of the recession in Western Europe continued to contribute to feed to the largely negative expectations about the unbalanced patterns in the Hungarian fiscal environment. Following harsh fiscal measures taken by a new conservative right-wing government both fiscal and external financial stability has improved substantially. In the early years of 20102014 there was a cost to be paid in terms of foregone economic growth. Later, growth has picked up substantially in the first quarter of 2018, thanks to the EU-cohesion funds flowing and still feeding investment-based growth, the stabilization policy overall can be labelled as successful.

\subsection{DATA AND METHODOLOGY}

In the next section we review and identify shock resistance metrics and apply these to some selected small open economies. Next, we graphically exhibit the Trilemma indices for a handful of small open economies, for the 1993-2014 period and classify adjustment patterns.

The methodology of measuring the shock resistance capabilities has improved a great deal over the last decade. Primarily, we rely on the resistance indices as developed by Rojas-Suarez (2015). The index is composed of 7 components, as Table 1 summarizes, following Rojas-Suarez (2015) definitions, the external financial vulnerability variables are as follows. 
Table 1 External shock resistance variable

\begin{tabular}{|ll|c|l|}
\hline \multicolumn{2}{|c|}{ Name of the component } & Variable & \multicolumn{1}{c|}{ Note } \\
\hline 1 & CA/GDP in $\%$ & $X_{1}$ & current account per GDP in per cent \\
\hline 2 & Total debt/GDP in \% & $X_{2}$ & conditional \\
\hline 3 & Short term debt/ reserves & $X_{3}$ & traditional \\
\hline 4 & Annual deficit/GDP \% & $X_{4}$ & traditional \\
\hline 5 & Sovereign debt/GDP \% & $X_{5}$ & traditional \\
\hline 6 & Error in inflation targeting & $X_{6}$ & relatively new variable \\
\hline 7 & $\begin{array}{l}\text { Change in financial vulnerability } \\
\text { over credit cycles }\end{array}$ & $X_{7}$ & this is a new variable \\
\hline
\end{tabular}

Source: Based on Rojas-Suarez (2015) the author's exhibit

Out of the seven variables, $X_{7}$ deserves some discussion since it is a clearly new measure of financial fragility, the so called FinFrag index.

The meaning of the new variable, X7:

$$
\text { FinFrag }=\left(d R C^{\text {boom }}-d R C t\right) *\left(d R C t-d R C^{\text {bust }}\right)
$$

where $d R C^{\text {boom }}$ is the upper bound to the change in credit creation cycle, $d R C^{\text {bust }} \mathrm{i}$ is the lower bound in the credit creation cycle, respectively, as defined by Rojas-Suarez (2015, pp. 15-18).

To create the composite index, then, we get it by taking the simple average of the 7 normalized $\left(X_{1}, X_{2} \ldots X_{7}\right)$ variables. Normalization means that we take the difference between the sample average AVGX, and the value for the respective country index and then, we divide by standard deviation of the sample, $\sigma_{\mathrm{x} 1}$. For instance, the normalized variable for the $\mathrm{i}^{\text {th }}$ country for $X_{1}$ looks like this:

$$
\mathrm{X}_{1}^{\mathrm{i}^{*}}=\left(\mathrm{X}_{1}^{\mathrm{i}}-\mathrm{AVGX}_{1}\right) / \sigma_{\mathrm{x} 1}
$$

Then we create

$$
S R I^{i}=\left(X_{1}^{i^{*}}+X_{2}^{i^{*}}+X_{3}^{i^{*}}+X_{4}^{i^{*}}+X_{5}^{i^{*}}+X_{6}^{i^{*}}+X_{7}^{i^{*}}\right) / 7
$$

If the increase in value of a variable does decrease the level of shock resistance, then, it gets multiplied by minus one (-1); the budget deficit/GDP is one such a variable for instance. The range of the shock resistance variable is spreading between -1.5 to +1.5 , the first is the worst the latter is being the best level possible. 
Graph 1 The change in external shock resistance capabilities of some selected small open economies (2007-2014)

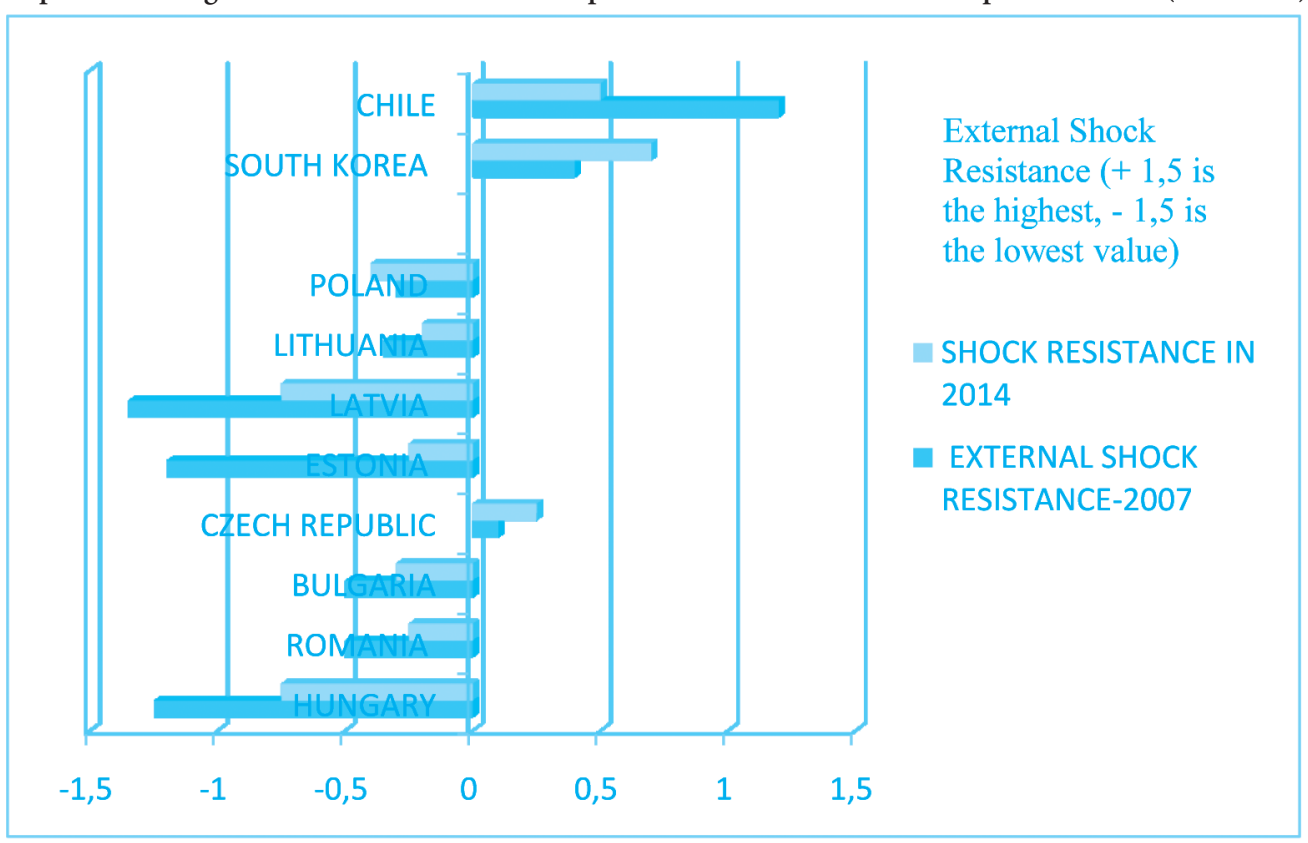

Source: Based on Rojas-Suarez (2015), the author's exhibit

Graph 1 depicts the changes that took place in the shock resistance capabilities of a selected group of countries with small open economies.

To help the comparison, a middle size open economy, Poland - with good levels of resistance - and two non-European countries, Chile and South Korea, were added. These countries have all shown strong resistance capabilities. Out of the Central-Eastern-European (CEE) economies, it was clearly the Czech Republic that stood out with her sharply positive numbers in both 2007 and in 2014. Lithuania, Latvia, Estonia, Hungary, on the other hand, proved to be very vulnerable during the crisis years, they slipped lower than the minus one (-1) negative zone mark. From Graph 1 in sum, it can be stated that there was a great variety in the shock resistance capabilities of small open economies. However, in general, the lower government-debt, higher levels of central bank reserves (like in South Korea, Chile, Czech Republic) could help a great deal to cushion shocks, and increase financial stability.

Based on the previous arguments, however, one is prompted to ask: do the particular trilemma paths chosen determine the shock resistance levels? The answer to this question is a definite NO, it does not: there is no unambiguous economic policy success which can be clearly associated with just one particular trilemma solution pattern. But this proposition is by far not trivial. So, to further elaborate, in the next section we shall review the modern extensions of trilemma metrics. 


\subsection{ReCENT Developments in The Measurability of THE IMPOSSIBLE TRINITY}

How can the success or failure of external adjustments patterns, and more importantly, the trinity choices measured?

This question, although in a somewhat different context, was asked well before the world economic crises, by O'Neill (2001) for instance. External adjustment metrics on solid foundations were first produced by Aizenman et al. (2013). To our analysis, we adopt the variable definitions and database offered by the Aizenman et al. (2013). Out of the three components, fx-stability, monetary independence, and capital account openness, the monetary independence seems the easiest to measure. The suggested metrics is following the correlation between in home-country key interest rates and those of the base country money markets.

The expression below captures this relationship and transforms it into value between 0 and 1 .

A/

$$
M I=1-\frac{\operatorname{corr}\left(i_{i}, i_{j}\right)-(-1)}{1-(-1)}
$$

The larger the value of this index the larger is the monetary independence in the given country. Base-countries are defined as the highest correlation pattern countries, typically key-currency countries, such as U.S., U.K., Australia and Germany. For a further and deeper discussion of the base-country choice, see Shambaugh (2004).

B/

On the $\mathrm{fx}$-stability, the trilemma matrix offers this convenient solution to have values between zero and 1: it takes the standard deviation of monetary $\mathrm{fx}$ rates stdev(exc_rate); and in absolute value $|d \log E t / d t|$ of the end of December prices.

$$
E R S=\frac{1}{1+\left|d \log E_{t} / d t\right|+0.01}
$$

Here too, higher values represent higher stability, and vice versa, lower values mean less stability.

C/

To create a binary variable for the capital account openness is the most difficult. Following a special methodology developed by Chinn-Ito (2008), we use the KAOPEN measures based on the IMF Annual Report on Exchange Rate Arrangements and Restriction (AREAER). The variables are the following:

$$
\operatorname{SHAREk}_{3, t}=\left(\frac{k_{3, t}+k_{3, t-1}+k_{3, t-2}+k_{3, t-3}+k_{3, t-4}}{5}\right)
$$

There are 4 types of capital controls:

$\mathrm{k}_{1}$ : Multiple exchange rates (market and official, bureaucratic)

$\mathrm{k}_{2}$ : Controls and limits on current account transactions

$\mathrm{k}_{3}$ : Limits on capital account transaction

$\mathrm{k}_{4}$ : Export-income-deposit requirements. 
In accordance with the other two trilemma indices, the capital account index, when it is highest, equals to one (1), and it means full openness and, when it is zero (0), it is the equivalent of a closed or totally isolated capital market.

\section{WHAT DO THE TRILEMMA INDICES SHOW?}

Table 2 Classification of some small open economies with respect to their Impossible Trinity profiles

\begin{tabular}{|c|c|c|c|c|}
\hline Impossible Trinity factors & $\begin{array}{c}\text { Type-A- } \\
\text { attributes }\end{array}$ & \multirow{4}{*}{$\begin{array}{c}\text { Countries Type-A } \\
\\
\text { HUNGARY, } \\
\text { CZECH } \\
\text { REPUBLIC, } \\
\text { DENMARK } \\
\text { ISRAEL, } \\
\text { CHILE, } \\
\text { SOUTH KOREA }\end{array}$} & $\begin{array}{c}\text { Type-B- } \\
\text { attributes }\end{array}$ & \multirow{4}{*}{$\begin{array}{c}\text { Countries Type-B } \\
\text { AUSTRIA, } \\
\text { SLOVENIA, } \\
\text { ESTONIA, } \\
\text { SLOVAKIA, } \\
\text { PORTUGAL, } \\
\text { GREECE }\end{array}$} \\
\hline Foreign exchange stability & $\mathrm{NO}$ & & YES & \\
\hline Monetary independence & YES & & $\mathrm{NO}$ & \\
\hline $\begin{array}{l}\text { Large degree of financial } \\
\text { integration/openness of } \\
\text { the capital account }\end{array}$ & YES & & YES & \\
\hline
\end{tabular}

Source: The author's specification

We have identified two types of adjustment patterns: Type-A countries, which were keeping their monetary independence and the large fx-changes as shock absorbers; and Type-B countries, which anchored themselves to a strong currency union, namely to the euro-zone and gave up monetary independence.

We start the analysis by type-A countries as listed in Table 2 . The representative pattern of adjustment was characterized by the lack of fx-stability and by monetary independence, while keeping the capital account open. To this type-A-group belong Hungary, the Czech Republic, Denmark, Israel, Chile and South-Korea.

We show the patterns of adjustment for one old (Denmark) and two newer CEE EU-member countries. One could detect quite a similar "trinity patterns" from Graph 2, Graph 3 and Graph 4 , respectively.

Following 1999, the capital account was to be liberalized gradually in all of the three selected countries, to be completely open by 2005 . The level of monetary independence was subject to variations, yet for central banks the overall trend was more of a losing trend than gaining authority with respect to their powers of making proper external adjustments (remember the higher index numbers reflect higher independence).

Monetary independence in Hungary was highest in 2004, in the year of joining the EU, and was lowest in 2013. The fx-stability of the Hungarian forint (HUF) was losing steam rather than gaining strength. The Czech koruna, to a lesser extent, but headed the same weakening direction. The Danish krone, on the other hand, did show a remarkable level of stability. The main factors behind stability were the low levels of public debt, and the historically well balanced foreign trade and financial flows with her main partners. 
Graph 2 The evolution of trilemma indices in Hungary (1993-2014)

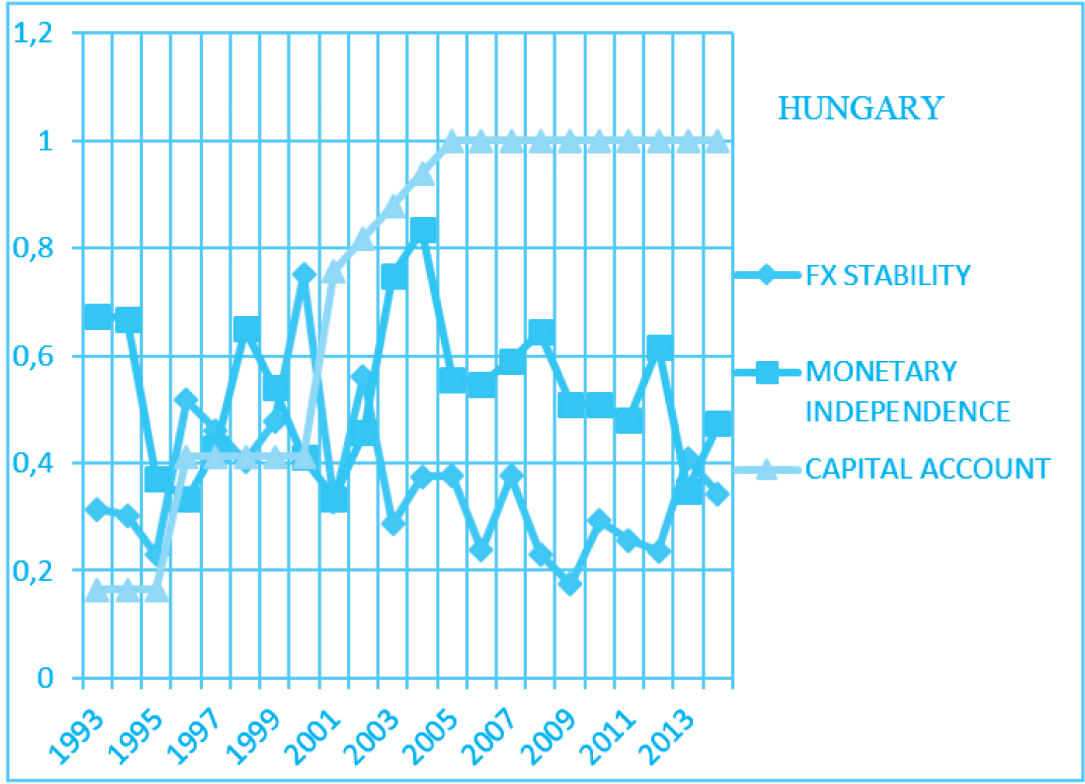

Source: Aizenman et al. (2013), IMF, AREAER $(2015,2016)$, the author's exhibit

Graph 3 The evolution of trilemma indices in the Czech Republic (1993-2014)

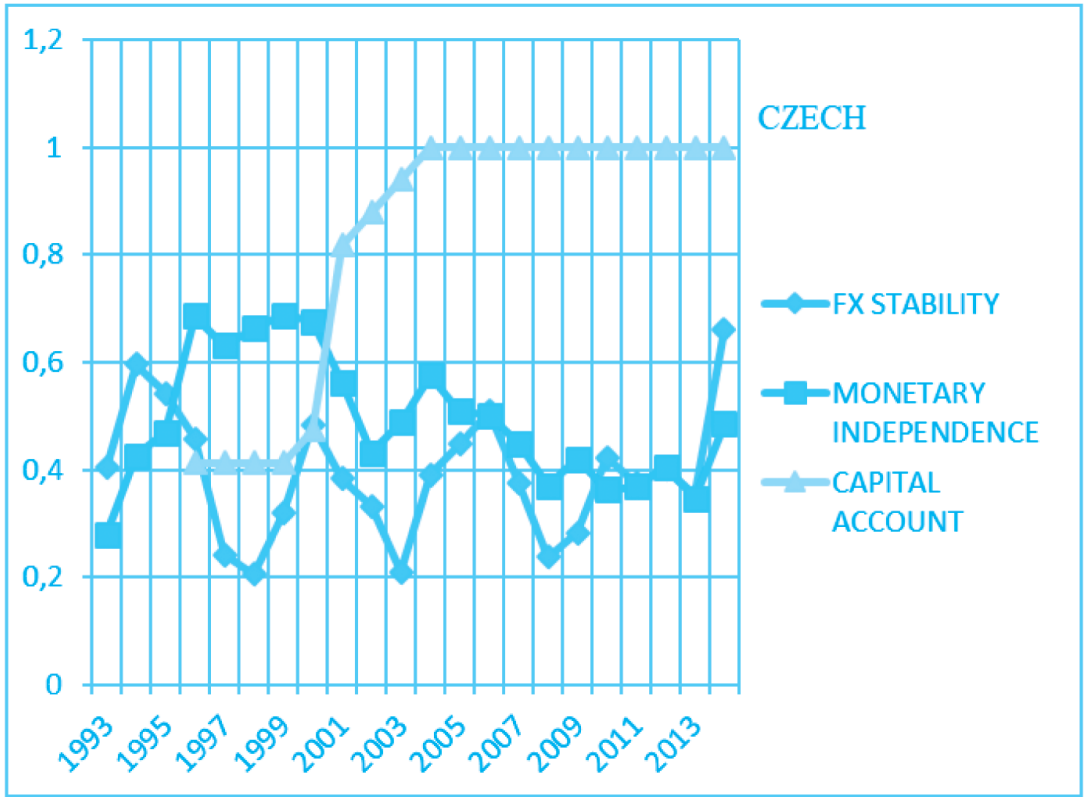

Source: Aizenman et al. (2013), IMF, AREAER $(2015,2016)$, the author's exhibit 
Graph 4 The evolution of trilemma indices in Denmark (1994-2014)

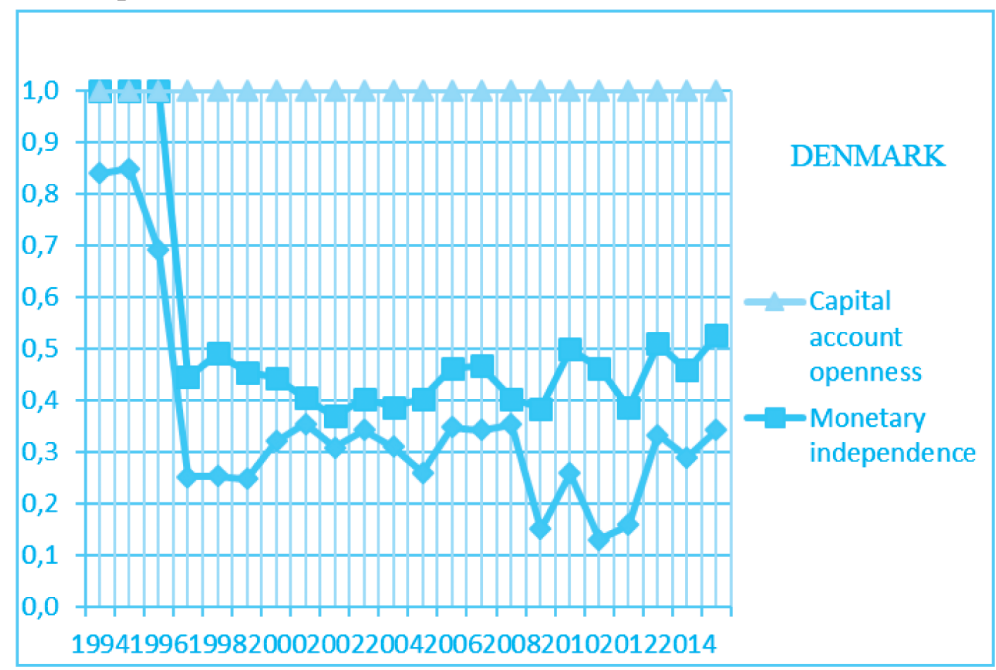

Source: Aizenman et al. (2013), IMF, AREAER $(2015,2016)$, the author's exhibit

To better understand the bigger volatility and the fx-policies used by the Hungarian and the Czech economies, we may look at another perspective of fx-adjustment, namely on the tradeweighted, nominal effective profile of the HUF, CZK, respectively.

The nominal effective exchange rate is determined as follows: the bilateral-trade weighted fx-rates are calculated as their geometric average (i.e. taking their multiples under the corresponding root) as defined against a base year in an index form: when currency indices are greater than 100, it means strengthening, or appreciation; less than a 100 is equated with weakening, or depreciation.

Graph 5 Nominal effective fx-rates Czech koruna, Danish krone and Hungarian forint $(1994-2016,2008=100)$

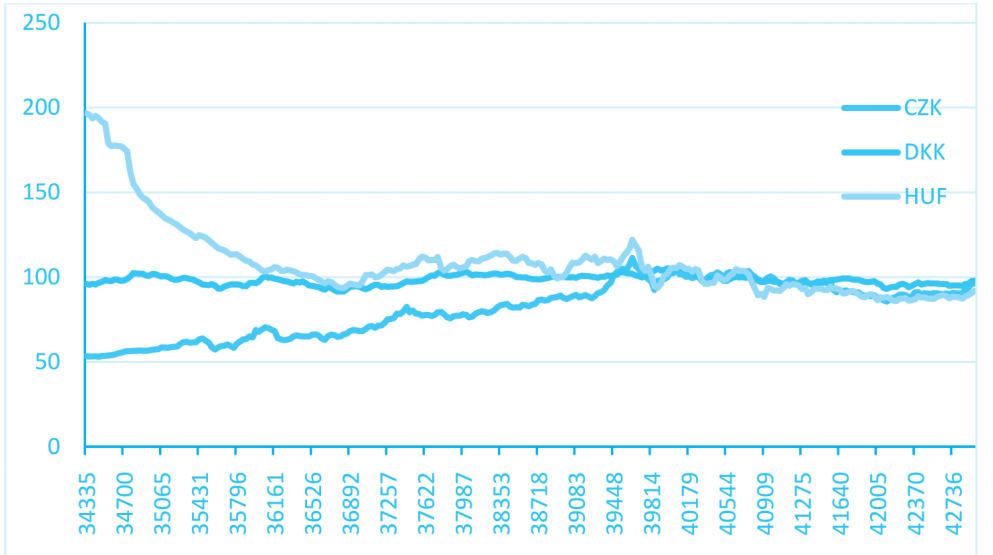

Source: Based on BIS data base, the author's exhibit 
As can be seen in Graph 5, when measured against the base-year 2008, from 1994 until 2000, Hungary and the Czech Republic showed opposite trends: the HUF was weakening; the CZK was strengthening vis-à-vis their main trading partners. Between 2000 and 2008 the koruna further strengthened. Following the 2008 crisis, up until today, the HUF has gone through further depreciation in the range of 10-15 per cent. In the post-crisis period, the Czech koruna also suffered from a weakening trend, although it was much lighter, 3-5 per cent on average. The Danish krone stability on the other hand was quite impressive.

An even more realistic picture can be depicted from Graph 6, which exhibits the so called real effective exchange rate trends for the two Eastern-European small open economies. The real effective rate index (REER) is the one that is adjusting the nominal rates for inflation thus giving a more realistic assessment of fx-rate changes. Up until the year 2000, both CEE economies witnessed slight real appreciation of their currencies. Since then, this pattern changed and exhibited a more markedly weakening real trend. But in the post-crisis period up until 2017, there was visibly much more stability in the fx-adjustments for all three countries analyzed.

To explain this phenomenon, we should incorporate the notion of overshooting relative to the purchasing power parity levels, and the full impact of asset markets well beyond the price formation of just the goods markets. The asset markets go the opposite way after heavy fx-volatility takes place.

Graph 6 Real effective exchange rates, Hungarian forint and Czech koruna (1994-2016, 2008=100)

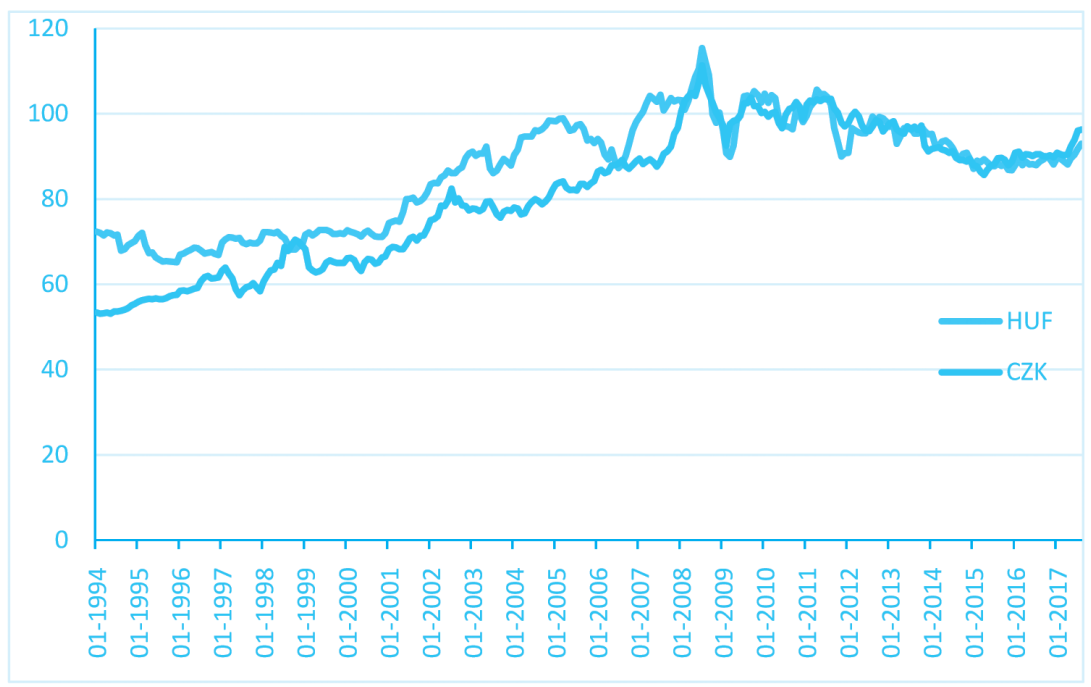

Source: Based on BIS data base, the author's exhibit

In sum, we may conclude that the resilient floating regimes could help to a large extent resist external shocks but, of course, they could not compensate for long lasting problems of large foreign indebtedness or those of international competitiveness. In countries where these historic problems did not exist, such as Denmark, well, there it was much easier an exercise to attain fx-stability. 


\section{Summary and Conclusions}

For the main question of the paper, whether for the selected group of advanced small open economies there was, or was not a standard and universally prevalent external adjustment pattern, the answer is a firm NO. The final conclusions of the study can be summarized as follows:

- Although both the theoretical and practical impossibility of the trilemma proposition has been held up, that is, from the available economic policy toolbox the simultaneous application of the fx-stability measures and the maintenance of monetary independence, with open capital accounts, was not and is just not possible; there were, and are even today, several alternative types of successful external adjustment paths that allow for currency stability and for the loss of monetary independence.

- Thus the two clearly classifiable patterns for this analysis were the type-A adjustment in which fx-volatility and monetary independence were dominant (e.g. Hungary, Czech Republic); and type-B in which fx-stability (practically a common currency, the euro) and the full giving-up of monetary independence, characterized the adjustment. Austria, Slovenia, Slovakia and Estonia were the strong small country representatives of such successful adjustment. Denmark was a borderline case, keeping its own currency, the Danish krone, and its sovereign monetary authority.

- However a good amount of caution is in order for some euro-zone countries, with Portugal and Greece in particular. Since in both of these euro-zone member countries the trilemma proposition simply did not and does not reveal all aspects of the shock resistance difficulties arising. It is obviously the fiscal dimension of the adjustment that may soon further complicate the external shock resistance profile, and more importantly, the home country's central bank capabilities to help growth and liquidity flow uninterruptedly. Without the fiscal dimensions, however, there is no complete external adjustment picture.

- In addition, on the more complex question whether it was somehow possible to identify which particular external adjustment pattern can be best labelled as truly and undoubtedly successful, we have not been able to arrive at a definitive conclusion. This is clearly a tougher academic assignment, which may only be addressed and thoroughly worked on only if some other key elements (such as the longer-term fiscal and international debtservicing profiles, the changes in the net international asset position, etc. of the country under scrutiny) are also incorporated. Limitations notwithstanding, one would, however, venture to claim that euro-zone membership itself - neither theoretically nor empirically -, even with the loss of monetary independence, does not represent a barrier to a good growth performance.

- Finally, a word on the most likely balance of costs and benefits of a foreseeable Hungarian euro-zone membership. The much recognized success of Slovakia, the Baltic states, and Slovenia suggest that there may not be any insurmountable obstacles in the way of keeping the requirements and still sustain economic growth. The benefits from a future stability and growth perspectives, may easily outweigh the costs. It must, of course, be added, however, that to overcome the currently existing problems in many dimensions of international competitiveness, whatever the power of the fx-regimes and monetary policy tools, maybe in Hungary there should be major and long lasting institutional measures 
introduced. That is a must do in order for any government to be able withstand the new different types of competitive and financial external pressures evolving either from the re-shaped EU and world economy. External shock resistance capabilities even if largely improved, do not substitute for sources of longer run growth and competitiveness. For small open economies that lesson remains just as timely to be learned as ever.

At last, on the special Hungarian focus we may conclude that for a non-euro-zone small economy, like Hungary, the external shocks meant more trouble and less defence abilities than for countries with larger domestic markets with a euro umbrella.

The Hungarian economy in the crisis period was characterized by an unusually high external debt, wide current account deficit, and a large external financing requirement, still-excessive fiscal deficits, maturity and currency mismatches in the financial system, both within the individual households as well as in the corporate sector. Hungary was too sensitive to movements in international capital markets since a considerable proportion of financing depended on flows from the western European parents to their Hungarian daughter-banks. In addition, foreign currency denominated loans accounted for a large portion of household and private sector credit as high domestic interest rates led them to take up credits in low interest currencies. As a result, both the household and the corporate sectors' net foreign currency liabilities increased at the worst possible time, raising indirect risk to the banking system. One can safely conclude that one of the small open economy's special vulnerabilities was that Hungary's government debt was to a large extent foreign-owned. Since 2014 until today, this strain has been eased substantially by channelling new debt to domestic savers and to the corporate sector. In the year 2018, the lowered budget deficit in GDP terms also helped stabilization policies a great deal removing obstacles from the road to a healthier and sustainable economic growth.

\section{REFERENCES}

Aizenman, J. (2010): The Impossible Trinity (The Policy Trilemma). Working Paper Series from Department of Economics, UC, SantaCruz,

http://econpapers.repec.org/scripts/redir.pf?u=http\%3A\%2F\%2Fwww.escholarship. org\%2Fuc\%2Fitem\%2F9k29n6qn.pdf\%3Borigin\%3Drepeccitec;h=repec:cdl:ucscec:qt9k2 $9 \mathrm{n} 6 \mathrm{qn}$

Aizenman, J. - Chinn, M. D. - Ito, H. (2013): The "Impossible Trinity" Hypothesis in an Era of Global Imbalances: Measurement and Testing. Review of International Economics, Vol. 21, No. 3, pp. 447-458.

Benczes, I. (2016) From Goulash Communism to Goulash Populism: The Unwanted Legacy of Reform Socialism. Post-Communist Economies, Vol. 28, No. 2. pp. 146-166.

Benczes, I. (2008) Trimming the Sails. The Comparative Political Economy of Expansionary Fiscal Consolidations. Budapest-New York: CEU Press.

Bohl, M. T. - Michaelis, P. - Siklos, P. L. (2016): Austerity and recovery: Exchange rate regime choice, economic growth and financial crises. Economic Modelling, Vol. 53, pp. 195-207., https://dx.doi.org/10.2139/ssrn.2696440 
Chinn, M. D. - Ito, H. (2008): A New Measure of Financial Openness. Journal of Comparative Policy Analysis, Vol. 10, No. 3, pp. 309-322.

Kenen, P. B. (1989): The International Economy. Second Edition. Englewood Cliffs, NJ: Prentice Hall. Chapter 15, pp. 313-328.

Mundell, R. A. (1968): Capital Mobility and Stabilization Policy under Fixed and Flexible Exchange Rates. Reprinted In: International Economics, New York: Macmillan, pp. 250-271.

Obstfeld, M. (2015): Trilemmas and tradeoffs: living with financial globalisation. BIS Working Papers, No. 480.

O'Neill, J. (2001): Building Better Global Economic BRICs. GS Global Economics Paper, No. 66.

Rojas-Suarez, L. (2015): Emerging Market Macroeconomic Resilience to External Shocks: Today versus Pre-Global Crisis. Center for Global Essay, https://www.cgdev.org/sites/default/files/ CGD-Essay-Rojas-Suarez-Emerging-Market-Macroeconomic-Stability_0.pdf

Shambaugh, J. C. (2004): The Effect of Fixed Exchange Rates on Monetary Policy. The Quarterly Journal of Economics, Vol. 119, No. 1, pp. 301-352. 